\title{
780 SAYIII BAZI SUÇ VE CEZALARIN AFFI HAKKINDA KANUN
}

\author{
Dr. Uğur ALACAKAPTAN \\ CEZA HUKUKU DOÇENTTI
}

9/Ağustos/1966 tarihli Resmî Gazete'de yayınlanarak yürürlïğe giren 780 sayıl Af Kanunu, Cumhuriyet devrinde yapilan Af kanunları arasında, şüphesiz, en çok ilgi çekeni ve üzerinde en çok tartışlanı oldu. Tasarı, daha Millet Meclisi'ne gönderildiği sırada kamuoyunun malı olmuş ve meclislerden geçip kanunlaşıncaya kadar, hukukçu olsun, olmasın, düşünürlerin, çoğunlukla menfî tepkilerine hedef teşkil etmiştir. Kamuoyunun tepkisi bununla da tükenmemiş, gösteriler, sempati ve protesto yürüyüşleri bile yapılmıştır. Tartışmalar, tasarı kanunlaştıktan sonra da kolay kolay dinmemiştir.

Türk kamuoyunu bu kadar ilgilendiren bir konuyu bir kez daha ele alıp, kanunun genel ilkeleri ve bazı hükümleri hakkindaki görüşlerimizi belirtmekte ve bundan sonra yaplacak af kanunlarında riayeti gereken hususlara işaret etmekte fayda olduğunu sanıyoruz (1).

\section{KANUNUN YAPILMA NEDENLERI :}

Kanunun, Bakanlar Kurulu'nca hazırlanmış olan grerekçesinde, «...sosyal, siyasî ve iktisadî bünyemiz bakımından toplumda husule gelen gelişmeler karşısında, işlenmiş bir kısım suçlara verilmiş olan cezaların çektirilmesinde ve bazı suçların takibinde içtimaî bir faide kalmamış ve affın sosyal bir tedbir olacağı inancı ve bir atufet olması niteliği»nin ıgöz önüne alınmış olduğu belirtilmektedir. Aslında, bu genel ve kapsamı belirsiz sözlerin geniş bir alanı kapsayan bir af kanununun temel gerekçesi olarak yetersizliği

(1) Tasarının önemli bazı hükümleri hakkındaki görüßslerimizi daha önce belirtmiştik: ALACAKAPTAN, Uğur. Af Tassarısı Eşitlik Hakkını thlâ] Ediyor, Yeni Gazete, 8/7/1966. 
aşikârdır. Ancak, belirli bazı sabıplerin gösterilmemะsi bir tesadiic yada unutkanlik yahut ihmâlden doğmuş değildir. Gerçekte, çoğunluğun kabûl edebileceği mukni bir sebep bulunamadığından ve asıl sebeplerin açıkça ifade edilmessinden çəkinildiği içindir ki bu yola gidilmiştir.

Mesele hukuk biliminin ilkeleri çerçevesinde ele alındı̆̆ında böyle bir kanunun yapılmasını zorunlu kulabilecek sebepleri bulmaḱ çok zordur. Belki, af kanununun yapılması değil, yapılmaması tezi savunulmak gerekirdi. Zira, çok partili demokratik hayata geçişimizden bu yana ve özellikle 27/Mayıs/1960 Devrimi'nden sonra, ilerisi düşünülmeksizin çıkartılan af kanunları, Ceza Kanunu'nun bir cok hükümlerini ve infaz kuruluşlarinı birer süs haline getirmiş łulunuyorlardı. Bugün, vatandaşta, bir suç işlediği takdirde cezasının tamammı nasıl olsa çekmeyeceği, bir kaç yıl içinde çıacak bir af kanununun, cezasının büyük bir kısmını alıp götüreceği fikrinin yer etmiş olciuğu, ne yazık ki doğrudur. Ancak, șu da coğrudur ki, balli amaçların gerçekleşmesi için çaba gösteren politikacllarla basın konuyu o derece çkmaza sürüklemişlerdir ki, doğuracağı bütün sakıncalara rağmein tasarının karşısında yer almağa, kanunlaşmasindan önceki dìvrede, imkân kalmamıștı.

Mamafih, affın böylece bir emrivaki şeklinde ortaya çıkmıs olması, kanun koyucuinun, her ne pahasina olursa olsun bu tasar:yı kanunlaştırma çabalarinin mazur va meşrû görüleceọ̆i anlamına alınmamalıydı. Çünkü, bütün yasama çalışmalarında olduğu gibi, af kanunlarinin hazırlanmasino da bazi ilkelere uyulması zoruniudur.

II. EŞITLLIK ILLKESI VE AF :

Af kanunlarında «eşitsizlik» kavramı bünyeleşmiștir. Gerçekten, kanunların aynı durumda olan herkese eşit şekilde uygulanması ana kural olunca, belli bir tarihe kadar işlenmiş olan suçlarm cezadan kurtulmasina mukabil, diğerlerine bir saat yada gün farkı yüzünden kanunların bütün şiddetiyle uygulanması, önce eşitlik, sonra adalet ilkeleri ile bağdaştırılamaz. Buna rağmen af kanunları yapıliyorsa, buna, toplumsal ve siyasal baskıların etkisiyle tevessül edilmektedir. Ancak, kanun koyucu, af kanunlarının bünyesindeki eşitsizlik ve adaTetsizlik unsurlarını daha bariz 
bir hale getirmemek için bu çeşit baskllara mümkün mertebe karşı koymak, hiç değilse, bazı esaslara uymak durumundadır.

'Türkiye Cumhuriyeti Anayasası'nın 12. maddesi, «k a $n$ u $n$ $\ddot{g} \mathrm{n} \ddot{\mathrm{u}} \mathrm{n} \mathrm{d}$ e e s i $t \mathrm{l}$ i k» ilkesini koymuştur. Af kanunlarının da bu ilkelere uyması garekir. Fakat, yukarıda da belirttiğimiz gibi «eşitsizlik» unsurunu af kanunlarının bünyesinçen söküp atma imkânsızdır. Bu durum karşısinda, ceza kanunlarına, af kanunı yapmak suretiyle istisnalar getirilmemesi gerektiği düşünülebilir. Fakat, «... af kanunlarını... sırf hukukî kriterlere dayanmak suretile incelemek, yani katı ve değişmez hukuk kalıpları içinde mütalea etmek» (2) her zaman mümkün olmaz. Kaldı ki, T.C. Anayasası 64. maddesinde T.B.M.M.nin görev yetkilerini sayarken, «genel ve özel af ilânını» da zikretmiş bulunmaktaäir. Binaenaleyh, af kanunlarını, bünyelerinde eşitsizlik ve adaletsizlik unsurlarını taşıyor diye ve sadece bu sebeple Anayasa'nın 12. maddesine ayk1rı saymak düşünülemez. Fakat, kanun koyucu bu olumsuz unsurları daha belirli hale getirebilecek tasarruflarda bulunduğu takdirde böyle bir kanuna karşı çıkmak için hukukî sebepler de doğmus olur.

Af kanunlarının, politik hüviyet tassıyan kanunlarin bașnda geldikleri iddia olunmuştur (3). Kanaatimizce, af kanunlarını yalnız hukukî ölçï ve kahplara göre değerlendirmek ve cezalandırmak hakkına hiç bir istisna tanımamak ne kadar sakıncal ise. affı siyasal amaçlarla kötüye kullanmak da o kadar sakıncalıdır. Çïnkü, politika, hukuka, hafifliği de birlikte getirir. Bunun için, politik unsurları af kanunlarında asgarî ölçüde tutmak gerekmektedir. Özellikle siyasal suçların affı söz konusu olduğunda, politik mülâhazaların af kanunlarının kapsamını ve kaderini pek fazla etkilediklerini Türk yasama organlarının çalışmalarına bakarak da görebiliyoruz. $\mathrm{Bu}$ etkilerin olumlu oldukları söylenemez. Çünkü, her şeyden önce eşitlik ilkesinin zedelenmesi sonucunu doğurmaktadırlar (4).

(2) ERMAN, 'S. id.

(3) KEYMAN, Selâhattin. Türk Hukukunda Af, 1965 Ankara, sah. XIII.

(4) Aynı etkenler, bir af kanunu ç̧ılkar çıkmaz, yeni af istemlerinin yapılmasın tahrik etmekte, slk slk çlkarllan kanunlar yüzünden cezaların muhakkaklığı ilkesi kuvvetini gittikçe yitirmektedir. 
780 sayllı kanunda bunun örneklerini hem siyasal hem adî suçlar bakımından görebiliriz.

\section{a) Siyasal Suçlar Bakımmdan :}

Af kanunlarının siyasal suç failleri hakkında çıartılmasının daha doğru olacağı ve devrimlerle ihtilâllerden sonra, geçmişteki kötü anıları silip barışı geri getirmenin bir yolunun da af olduğu ileri sürülmüştür. 27/Mayıs/1960 Devrimincien beri ülkemizde en çok ortaya atılan sebep de budur. Gerçi, siyasal suç faillerinin affında bazı faydalar bulunduğu doğrudur; fakat, somut bir yasama tasarrufu söz konusu olduğunda belirli bir takım siyasal suçların diğerlerinden ayrı tutulması ve ayrıcalıklı bir işleme konu teşkil etmesinin hoşgörülemeyeceğini sanıyoruz. 780 sayll kanunun bu yanlış yola girdiği, çeşitli kanallardan gelen teklif ve ikazların -belki de parlâmento dışındaki baskı gruplarının etkisiyle- nazara alınmamış oldukları görüilmekteăir.

Kanunun 5. maddesi ile «...Yüksek Adalet Divanınca mahkûm edilenler, fer'î ve mütemmim cezalar ile mahkûmiyetlerinin neticelerine de şamil olmak üzere affedilmişler...» ve Yüksek Adalet Divanı'nca sonuçlandırılamamıs olmaları sebebiyle Anayasa Mahkemesi'ne veya diğer kaza mercilerine intikal etmiş dâvaların sanıkları ile Yüksek Adalet Divanı'nca duruşmalarının muvakkaten ta. tiline karar verilen sanıklar ve Anayasa Mahkemesi'nin Kuruluşu ve Yargilama Usûlleri Hakkındaki Kanunun geçici 7. maddesinin 4 üncü bendi gereğince dosyalar Millet Meclisi Başkanlığına verilmiş bulunanlar hakkında kovuşturma yaplamayacağı hükmü konulmuştur.

Yüksek Adalet Divanı'nca, mahkûm edilenlerle, haklarında muvakkaten tatil kararı verilenlerin büyük bir çoğunluğu T.C.K. nun 146. maddesini, yani, Anayasayı ihlâlden hükümlü ya da sanıktırlar. Yasama organi, bunları toplum hayatına tamamen geri göndermektedir. Adı geçenler, Anayasa ve bazı özel kanunlardan gelen ve doğrudan doğruya siyasal hayat ile ilgili bazı yasaklar dişında, ceza mahkûmiyetinden doğan bütün ehliyetsizliklerder kurtulacaklardır. Buna karşllı, 21/Mayıs/1963 tarihindeki silâhlı kalkışma hareketiyle Ceza Kanunu'nun aynı maddesini ihlâl etmekten hükümlü şahıslar, aynı genişlikte bir affa lâyık görülmemişlerdir. Gerçekten, adı geçen hükümlülerden sadece sekiz yıl 
veya daha az hürriyeti bağlayıcı cezaya hüküm giymiş bulunanlar genel affa tabi tutulmuşlar, bunlar dişında kalanların cezalarından sekizer yll indirilmiş, ölüm ve müebbed ağır hapis cezaları onbeş yll ağır hapis cezasına indirilmiştir.

Aynı suçtan mahkûm oldukları hâlde, bu hükümlülerin farklı işleme tutulmalarını hukuken izaha imkân yoktur. Affın bir atıfet muamelesi oluşu, aynı durumda olan kişiler hakkında bu derece farklı sonuçlar doğuran tasarruflara girişilmesini mazur göstermez. Sebeplerin siyasal olmalar çok kuvvetle muhtemeldir. Basinda ve parlamentodaki görüşmelerde, «eski devrin restorasyonu», «intikam duygularının tatmini», «Ordunun 21 Mayısciların affına karşı olduğu» gibi çeşitli sebepler ortaya atılmıştır.

İktidarı tutan basında, Yassıada hükümlüleriyle 21 Mayısçılar arasınca — fiillerinin aynı kanun maddesini ihlâl etmiş olmasına rağmen - fark bulunduğu, Demokrat Parti ileri gelenlerinin silâhlı bir kalkışmanın faili olmadıkları, suçlar arasında vahamet farkı bulunduğu ileri sürülmüştür. Kanaatımızca, bu görüş, hukukî temelden yoksundur. Kanun koyucu, T.C.K.nun 146. maddesinin tanımladığı suçun, şu yada bu vasita ile işlenmesi arasında her hangi bir fark görmemiştir. Kanunun amacı, hukuka aykırı yol ve vasitalarla Anayasa düzenini ihlâle müteveccih hareketleri tecrim etmektir. Bu bakımdan, kanun koyucunun, suçun ana unsurları bakımından tefrik sebebi saymadığı bir şeyi, o suçun affı söz konusu olduğunda nazarı itibare almağa kalkışmakla mesele çözümlenmiş olmaz.

Esasen, siyasal suçlar arasında yapılan ve ayrıcalıklı bir zümre yaratan tefrikin bilimsel bir ölçüye dayanmadığı, affın kapsamı dissında bırakılan diğer suçlar ele alındığında da anlaşılmaktadır. Bunlardan 141 ve 142. maddedeki suçlarm, Devletin şahsiyetini ve Anayasa düzenini ihlâl etmiş olma!arı yüzünden pek vahim sayıldıkları ve bu gerekçeyle affın dışında bırakılmış olduklar akla gelebilir. Fakat, unutulmamalıdır ki, siyasal suçlamn çoğunda bu nitelik vardır ve af dışnda birakılan bu gibi fiiller herhâlde T.C.K.nun 146. maddesinin öngördüğï fiiller derecesinde vahamet arzetmezler. Kaldı ki, kanun, 146. madde dışında kalıp da başka bir cepheden Anayasa düzenini yıkmağ amaç edinen suçların faillerini affın çerçevesine sokmuş bulunmaktadır. Örneğin, «Lâikliğe aykırı olarak, Devletin içtimaî veya iktisadî veya 
siyasî veya hukukî temel nizamlarını, kısmen de olsa dinî esas ve inançlara uydurmak amacıyla... dini veya dinî hissiyatı veya dinç mukaddes tanlan şeyleri alet ederek her ne suretle olursa olsun propaganda yapan veya telkinde bulunan...» (5) kimseler hakkında kovuşturma yapılamayacak yada verilmiş olan cezalar çektirilmeyecek, hüküm, cezaî sonuçların tümünü kapsamak üzere ortadan kalkacaktır.

Öte yandan, Anayasa Mahkemesi, 141 ve 142. maddelerin, Anayasaya aykırı olmadıkları yolundaki, gørekçesi açıklanmayan kararına rağmen, bu madảelerde yer alan suçları tanımlayan hükümlerin ceza kurallarında bulunması gereken açıllk ve kesinlikten yoksun oldukları şeklindeki kanaatı silememiştir. Bu seber. le, adı geçen maddelerin, değişiklik yapılarak gerçek hüviyetlerine kavuşturulmaları beklenmeksizin atıfet muamelesine başvurulması gerekirdi.

$\mathrm{Bu}$ noktada şunu hemen belirtelim $\mathrm{ki}$, bu maddelerde yasaklanan yıkıcı faaliyetleräen dolayı yapılan kovuşturmadan vazgeçilmesi yada verilen cezanın affedilmesi, o suçların toplum yadx yasama organı tarafından hosggörüldüğ̈̈ anlamına galmez, Sahte. kârlık, adam öldürme, hakaret gibi suçların affedilmesiyle, komünistlik, diktatorya taraftarlığı, anarşistlik, irkçılık suçlar:nın affedilmesi arasında bu bakımdan her hangi bir fark yoktur. Eğer affedilerek serbest hayata yeniden kavuşacak bu gibi kimselerin, afdan cesaret alıp aynı suçları yeniden işleyeceklerinden endişe edi. liyorsa (6), bu endişeyi kanunun 11. maddesinin karşlladı̆̆ını hatırlatmak isteriz. Ad̊ geçen maḋde hükmüne göre, «...kanunun 1.

(5) T. C. K. madde 163 f.4

(6) ERMAN, is. id:: «...Bu gibi hallerde çekinilebilecek yegâne husus şudur: Bir siyasî suçlunun, hürriyeti bağlayıcı bir ceza ile-tıpkı âdî suçlula: gibi - uslan.nası mevzubahisı olmaz, zira siyasî suçlunun uslanması demek, belirli bir toplum bakımindan muayyen bir devrede zararlı görülen düşünce ve faaliyetlerinden vazgeçmesi demektir $k \mathbf{i}$, şimidiye kadar herhangi bir hürriyeti bağlayıc cezanin böyle bir sonuç doğurduğu görülmemiştir. Binaenaleyh, bu gibi kimseler hakkında hükmedilen hürriyeti bağlayıcı cezadan beklenen fayda, muzır telâkki edilen bu nevi faaliyetlerin devamina engel olmaktan ibarettir. Bu itibarla, bu gibi suçlular affedildikte, aynı faaliyetlerine devam edeceklerinden endişe edilebilir.» 
maddesinin (A) bendi dişında aftan faydalanan hükümlüler (7), kanunun yürürlüğe girdiği tarihten itibaren, mahkûm oldukları cezanın zaman aşımı süreși içinde ve her hâlde beş yll zarfında, taksirli suçlar hâriç, aşağı haddi altı aydan az olmayan hürriyeti bağlayıcı cezayı müstelzim aynı cinsten diğer bir cürüm işledikleri takdirde, evvelce haklarında hükmedilmiş bulunan cezanın infaz edilmeyen kısmı aynen çektirilir.»

\section{b) Âdi Suçlar Bakımmdan :}

Cumhuriyet devrinde yapılan af kanunlarında, bazı suçların affın kapsamı dışınđa bırakıldıkları, görülmektedir. Bu geleneği 780 sayılı kanun da devam ettiriyor. Bir kısım suçlar, hemen bütïn af kanunlarında, atıfete lâyık görülen fiiller dişında bırakılmışlar, diğerleri ise, bazen affın kapsamı içinde bazen dışında kalmışlardır. Şunu hemen belirtelim ki, bu ayrım yapılırken objektif ve kabûle şayan bir ölçüye istinad edilmiş oläuğu söylenemez. Örneğin, kanun koyucu, hemen hemen bütün af kanunlarında en ağir cezayı gerektiren suçların cezalarında indirim yaptığı hâlde, emniyeti suiistimal, dolandırıcıilı, basit zimmet gibi fiilleri affa lâyık görmemiştir.

Bu sakıncalı yol 780 sayılı kanunu yapanlar tarafından terkedilmiş değildir. Adam öldürme, sahtekârlık, irtikâp, rüşvet suçlarıyla, «...kanunlarm, suçu tesbit eden aslî maddesinde yukarı haddi beş seneyi geçmeyen hürriyeti bağlayıcı bir cezayı...» gerektiren fiiller ve beş yıl veya daha az hürriyeti bağlayıcı bir cezaya hüküm giymiş olanların cezaları kısmen yada tamamen affedildikleri, hatta, beş yıldan fazla cezayı gerektirmeyen fiiller, genel affın bütün sonuçlarından istifade ettirildikleri halde, örneğin, 510 . maddede öngörülen hizm气t sebebiyle emniyeti suiistimâl, zina gibi cezalarının yukarı sınırları beş yıldan çok aşağıda olan ve yalnız hapis cezasını gerektiren suçlar nedense affa tabi tutulmamıșlar-

(7) Kanunun 1/A bendindeki hükü̈m şudur: «Taksirli cürümlerle kanunların suçu tesbit eden aslî madidesinde yukarı haddi beş seneyi gȩ̧̣meyen hürriyeti bağlayıcı bir ceza ile yahut yalnız veya birlikte para cezası ile cezalandırdığı veya müsadereyi yahut bir meslek veya sanatın yapllmamasını veyahut bu cezalardan birini veya birkaçını istilzam eden filller hakkında takibat yapılmaz.» 
dır. Hele bu suçlardan zinanın yabancı ülkeleräe suç olmaktan çıkarılması yoluna gidildiği vakıası ile mezkûr suçu afîın kapsamı dışında bırakan hüküm arasındaki çatışma daha da. barizdir (8).

Icra ve İflâs Kanunu'nun 337 - 340 ve 344 . maddelerindeki suçların da, örneğin, cezalarının üçte ikisi indirilen irtikâp, rüşvet, sahtekârlık, emniyeti suistimal ve dolandırıcılık suçlærindan daha vahim fiiller saylarak istisnalar listesine sokulmus olmalarının da sebebi meçhûller arasında kalmıştır.

\section{OBJEKTIF ÖLÇÜ :}

Adaletsiz ve haksız istisnaların listesi çok uzundur. Bunun sebebi, affedilmiş suçlarla, tümden yada kısmen af tasarrufu dışında bırakılacak suçlam biribirinden ayırırken, sabit-objektif bir ölçünün seçilmesine itina gösterilmemiş olmasıdır. Affın dışında bırakılacak suçların tayininde sayma, yani, madde numarasıyla yada ismen gösterme usûlünün seçilmesi, ya yukarıda işaret olunan cinsten adaletsizlik ve haksizlıklara yada tavsif hatalarna vücut vermiștir. $\mathrm{Bu}$ bakımdan, kanunun 1 . maddesinin $\mathrm{A}, \mathrm{B}, \mathrm{C}$ ve $\mathrm{D}$ benälerinde kabûl edilmiş olan, «taksirli cürümler», «beş seneyi geçmeyen hürriyeti bağlayıcı ceza», «miktarı ne olursa olsun para cezasını gerektiren bir suçtan» sanık yada hükümlü olmak gibi ölçülerden, müteakip maddelerde uzaklaşlmasayd, bir yandan eşitlik ilkesinin ihlâlinin đerecesi asgarî hadde tutulmuş, yıldırımları üzerine çeken adaletsiz uygulama önlenmiş, öte yandan, belli bir ilkeye bağlı kalınarak hazırlanmış bir af kanununa ilk kez vücut verilmiş olunacaktı.

Sayın Prof. Erem'in, söz konusu Af Kanunu için vermiş olduğu özel notunda belirttiği şu görüşünün doğruluğuna yürekten inanıyoruz: «Geleneğe göre yapılan Kopya-Af Kanunlarında en ağır cezalı umumî suçlardan bile indirim yoluna gidilmesine mukabil, bazı fiillerin af kanununun şûmulü dışında bırakılması ceza hukuku tekniğine de uygun değilāir. Çünkü, suçların vahametini tayir. de objektif ölçü, o suçlara, kanunların suçların işlenmesinden evvel (dolayısile af kanunundan evvel) verdiği cezalardır. $\mathrm{Bu}$ suretle Ceza Kanunlarınca gerek ceza bakımından, gerek umumî ka-

(8) Aynı mahiyette, ERMAN, s. Siyasî Suçlar. Milliyet 28/7/1966 
nun sistematiği bakımından tesbit edilmiş bir ölçüyü af kanunlarında değiștirmek isabetli dieğildir.»

\section{AFTAN, ONA LÂYIK OLANIN FAYDALANMASI GEREKİR :}

Kanunda, aftan, ona lâyık olanın faydalanması gereğine de tamamen riayet edilmemiş olduğu görülüyor. Örneğin, hâkime, durumu, affın genel şartlarına uygun olmasına rağmen, bir sanık yada hükümlünün affa lâylk görülmediğine karar vermek yetkisi tanınmamıștır. Af bir atıfet tasarrufu olduğuna göre, hâkime ta. nınacak böyle bir yetkinin, kanun koyucunun gerekçe göstermeksizin kullanabileceği bir yetki alanına tecavuiz teşkil edeceği äüşünülebilir. Ancak, affa lâyık olmadıkları hâlde, sadece affın genel şartlarına uygun bir hukukî statüye sahip bulundukları için toplum hayatına yeniden gönderilen suçluların pek kısa bir zaman içinde Adalet binaları ve cezaevlerinin yolunu tuttuklar bir vakıadır. Ve yalnız bu vakıa, toplum yararı söz konusu olduğunda, kanun koyucunun yetki alanına tecavïz etmeme gibi soyut bazi maximlere bağlı kalmaktaki isabetsizliği göstermeğe yeter. Kaldı ki, hâkime verilmesi istenen bu yetki, kenäisine kanun koyucu tarafından verileceğine göre, bir yetki tecavüzünden de bahsedilmemesi gerekir. Esasen, 780 sayılı kanuna göre dahi, affın bazı hallerde uygulanmaması yada affedilmiş cezanın infazına devam edilmesi mümkündür. Tekerrür hükümlerinin uygulanmasını gerektiren «aynı cinsten suçlar»1 affın dişında bırakan hüküm ile (9), aftan sonra en çok bes yil içinde, taksirli olmayan ve en az alt ay hürriyeti bağlayıcı cezayı gerektiren aynı cinsten bir suçun işlenmesinin affedilen cezanın infazı sonucunu doğuracă̆ını bildiren hüküm (10) bu amaçla sevkedilmişlerdir.

Ancak, yalnız tekerrür hükümlerinin, affa liyakat yadła lyyakatsızlı̆̆ tesbit edebileceğine inanmaktaki hata küçümsenemez. Gerçi, belli bir süre içinde yeni bir suç işlenmesinin aftan faydalanma imkânını kaldırmasıyla, münhasiran objektif durumlara bakılarak yapılmış salıvermelerin sakıncaları kısmen giderilmiş olur; fakat, sanı yada hükümlüdeki ahlâk kötülüğünün ve tohli-

(9) 780 Sayllı Kanun, m. 10, f. 1

(10) Ayni Kanun. m. 11 
keliliğin fazla olduğu hâllerde, gerekirse af kanununu uygulamamak yada uygulamakla beraber, ihlâlinin müeyyidesi, ceza€vin؛ dönüş olan bazı şartlar koşmasını mümkün kılacak yetkileri hâkime tanıan bir sistem daha etkili ve faydalı olabilir.

\section{SUÇTAN ZARAR GÖRENIN KORUNMASI :}

Esas itibarile suçun doğurmuş olduğu cezaî sonuçlar göz önüne alınarak yapilan af kanunlarında, bu tasarrufun, suçun mağdurunda yaratabileceği tepkiler hesaba katılmamaktadır. Gerç, kanun koyucunun Devlet adına vazgeçtiği ceza kovuşturması yapma, ceza àavasını yürütüp sonuçlandırma ve cezalandırma haklarının, affın konusuna giren suçlar bakımından hüküm ifade edebilmesi için, affı suçtan zarar görenin tasvibine bağlamak, müessesenin bünyesine uymadığı gibi gerçekçi bir tatbikat da olmaz; ancak, affa uğrayan suçun mağdurunun, başka yollardan tatmin edilmesi mümkünđür. Zaten, bir çeşit «mânevî tatmin» olan cezanın, mağduru tamamen tatmin ettiği söylenemez (11). Bunun yanında, suçtan doğan zararı̀n ödetilmesini mecburî kılan bir sistem, hiç değilse, af kanununun uygulanması şartı olarak getirilmeliydi. Kanunun 9. maadesinin (2) numaralı bendinde, affin uygulanması, zimmet ve ihtilâs suçlarından ötürü hükmen tesbit edilmiş olan zararın tamamen ödenmesi sartına bağlanmıştır. Bu hükmün, affa konu teşkil ediecek bütün suçlar hakkında uygulanabilecek bir biçimde genelleștirilmemesi için hiç bir hukukî engel yoktur. Yani, kanun koyucu, bir zarar doğuran ve affın kapsamına giren bütün suçlarda af hükmünün uygulanmasını, zararın ödenmiş, hiç değilse teminat altına alınmış olması şartına talik edebilirdi. Bunun yapılmamış olması, «...insanın aklına, Devletin, kendi maruz kaldığı zararı ödetmek için... bu hükmü koyduğu, buna karşılık ferdlerin zararlarının tazmini ile uğraşmadığı ve af karşılı̆ında olsa bile bu zararları tazmin ettirmenin çaresini düşünmediği...» fikrini getirmekteäir (12). Oysa, af kanunlarının, suçtan zarar görenlerin tepkisini hesaba katıp, onlar tatmin im. kânlarını tesbit etmesinde zorunluluk vardır. Tecil müessesesinin.

(11) EREM, Faruk. 'Türk Ceza Huksuku, Genel Hükümlen, I. sah. 406, Ankara, 1966.

(12) GRMAN, S. Af, ve Uygulama Tarihi. Milliyet, 29/7/1966 
hatta meşruten tahliyenin böyle bir şarta bağlanması mümkün iken, af söz konusu olduğunda değişik bir yol seçmenin makûl bir sebebi bulunmadığını sanıyoruz.

Devletin, suçun ssbsbiyet verdiği kişisel haklarla ilgilenmediği yolunđaki kanaatı silmek için bir başka çâre daha akla gelmek. tedir: "Müōahale yoluyla vaki tazminat hakkındaki talep, Af kanunu, davanın hangi safhasında yürürlüğe girmiş olursa olsun, dâva ceza mahkemesinde bu hususa münhasir olarak devam edebilmeliőir» (13). Bu bakımdan, kanunun 17. madảesinin 2. fıkrasında yer alan, «Mahallî mahkemeler peşin ilâm harcını tamamlattıktan sonra dâvaya devam ederler» hükmünü yerinde bulmaktayı.

\section{HAZINE ALACAKLARINDAN VAZGEÇME :}

Kanunun 5. maddesinin 2. fıkrasında, Yüksek Adalet Divanınca verilmiş «mahkûmiyetler dolayısile hükmedilmiş olup da kanunun yürürlüğe girdiği tarihe kadar ödenmemiş olan zararların ödettirilmeyeceği ve 7 . maddesinde, «Genel Bütçe harcamalari sırasında hizmet karşllıklarının usulsüz ödenmesi dolayısile, yetkililer tarafından (Haksız iktisaplar hariȩ) bütçe hizmetlerinden doğma eşhas borçları hesabına aldırılan, vergi resim 've harç dişında kalan ve Sayıştay ile Askerî ve Adlî mahkemelerce suç ile - alâkası bulunmayan ve sorumlular adına hükme bağlanmış Devlet. alacakları ile, hizmet ifa ve belgeleri saymanlıklara teslim eāildiği hâlde mahsubu yapılamamış, ahizi üzerinde kalm'ş olan bütçeden mütevellit avans artıkları»nın silineceği hükmü konulmuştur.

$\mathrm{Bu}$ hükümler, Devlet'in suç sebebiyle tazminat ve alacak talep etmek hakkıyla, cezalandırmak hakkını biribirine karıştırmıştır. Af kanunları, suçlardan doğan cezaî sonuçları etkileme üzere yapilırlar. "Genel af, hiç bir zaman fiilin zarar verici mahiyetine tesir etmez. Çünkü, bu, fiilin suç teşkil edip etmemesine bağlı değildir.: (14). Binaenaleyh, af kanunlarının, suçun sebebiyet verdiği kişisel haklara - bu haklar, tüzel kişi sıfatı ile Devlet'e ait olsalar bile- etkide bulunmamalıdır. Bu ilke, T.C.K.nun 110. maddesinde

(13) EREM, F. Af Kanunu Tasarısı İçin Özel Not.

(14) KEYMAN, S. op. cit sah. 128 
açıça hükme bağlanmıştır. Kişisel hakları isteme bakımından bir özel kişiyle Devlet arasında fark yoktur. Bunun için, kanunun, Devlete ait alacak haklarının talep edilmeyeceği hakkındaki hükmünü, sadece, bazı siyasal gerekçelerle izah etmek mümkündür.

\section{KANUNUN GEÇERLIK TARIHI :}

Tasarı'nın 29/10/1965 olarak tesbit ettiği geçerlik tarihinin, Meclislerde 5/Haziran/1966 olarak değiştirilmiş olmasının yarat. tığı bir meseleye temas etmek istiyoruz: Eğer affın geçerlik tarihi, kanun tasarı veya teklifinin Parlamento'ya verilmesinden sonra değiştirilir ve daha ilerideki bir güne alınırsa, bunun, affın kapsamına gireceği duyulan suçların işlenmesini teşvik etmesi, yada memleketimizd̄e dedikodusu yapıldığı gibi, bu suçların faillerini, nüfuzlu kișiler yada mensubu yahut taraftarı oldukları siyasal partiler kanaliyla parlamento üyelerine etkide bulunma çarelerini araştırmağa sevkeder. Her iki halde de, sadece adalet ve kanuna saygı esası zarar görür. Bu bakımdan, bu son af kanununun hazırlanış ve çıkarılışı sırasınàa geçerlik tarihinde yapılan değișikliği tasvib etmiyor ve bu çeşit uygulamaları önleyici hükümlerin mevzuatımıza getirilmesi gerektiğine inanıyoruz.

Öyle sanyoruz ki, af kanun tasarılarının yasama meclislerine sevkinden sonraki tarihlerảe işlenecek suçların aftan faydalanamayacakları hükmünü koyan bir hüküm bu konudaki kötüye kul. lanmaların önüne geçebilecektir.

\section{BAZI U'SÚL MESELELERİ :}

Mevzuatımızın, af kanunlarının uygulanmasına ilişkin usûl hükümleri yeterli değildir. Bu sebeple, af kanunlarının yürürlüğe girmelerinden sonra, mahkemeler, sorgu hâkimlikleri ve savcılıklar tarafından verilecek kararın niteliği, affı kabûl etmeyen sanığın dâvasının görülmesine devam edilip edilmeyeceği gibi konularda çeşitli fikirler ileri sürülmekte, boşlukların bazen içtihaden doldurulması mümkün olmaktadır.

Biz, son senelerde çıan bazı af kanunlarında yer verilen «affı kabûl etmeme; müessesenin genel bir hüküm olarak ceza kanunumuza ilâve edilmesine taraftarı. (15) Çünkü, «afla cezadan

(15) Aynı mahiyette KEYMAN, s. op. cit. sah. 139-40 
kurtulan maznun, daima bir itham altında kalmıs olacaktır. Halbuki, suçsuzluğunun ortaya çıkacağından emin olan sanıklar, dâvanin neticelenerek kendilerinin ithamdan kurtulmalarını isterler. Bu, psikolojik bir ihtiłaçtır» (16).

Öte yandan, İtalyan Usûl Kanunu'nun 592. maddesinde yer alıp, genel affın, hâkimin, kamu dâvasıyla ilgili başka bütün meseleleri inceleyerek karara bağlamak yetkisini bertaraf edeceğini belirten hükme paralel bir hükmün de büyük bir ihtiyaca cevap vereceği aşikârdır.

(16) özEK, Çetin. Umumî Af, t. Ư. H. F. M. Cilt. XXIV, Sayı 1-4. sah. 171 